\title{
Dialogue between Moscow teachers and parents about the quality of preschool education
}

\author{
Igor Shiyan ${ }^{1 *}$ and Tatiana Le-van ${ }^{1}$ \\ ${ }^{1}$ Moscow City University, Institute of System Projects, Laboratory of Child Development, Moscow, \\ Russia
}

\begin{abstract}
Involvement of parents and teachers into decision making about evaluation criteria allows to establish partnership relations, confidence and awareness in implementation of preschool education programs. Such dialogue is necessary at the stage of transition to new norm, implementation of new national standards. In order to reveal the concepts of teachers and parents about good kindergarten, the research was carried out (anonymous survey using standard toolkit of European Quality Seal international project). The participants were 57 teachers and 284 parents from 26 Moscow schools with full-day preschool groups. The point of view of 18 experts in the field of preschool education was presented additionally. In general, the proposed criteria are important for respondents of all categories. Teachers demonstrate higher mean values in comparison with parents. Teachers and parents often have the same concepts about the value of these or those provisions: participation of parents in learning process as well as fee from parents are not important. Child-adult interaction, child's well-being and safety are the main priorities. The experts partially agree with teachers and parents concerning the most and the least significant criteria: among the most important, together with well-being, individualization of education and free play time are highlighted. The survey results can provide an objective ground for dialogue between teachers, parents, and authorities both at the level of ECEC service and at municipal, regional, and federal education system levels.
\end{abstract}

Keywords: preschool education, quality criteria, teachers' concepts, parents' concepts.

\section{Introduction}

Involvement of parents and teachers into kindergarten image making is a common practice. However, decisions about reforms of education are often made without participation of these positions: teachers should perform changes with minimum professional development, monitoring, and support [1,2]. The essence of changes is explained to parents by stakeholders very rarely. This impacts the satisfaction of the parties with each other and hinders implementation of reforms. Implementation of reforms could be supported by dialogue,

\footnotetext{
* Corresponding author: shiyanib@mgpu.ru
} 
which assumes that the parties accept each other's positions and establish conjoint understanding of quality concept [3].

The first step in making dialogue between politicians, practitioners, and families of preschoolers is fixation of initial positions of the parties. This is based on the concepts of attitudes (evaluation of obtained experience), expectations (desired image), and believes (images of generalized reality).

In the Russian practice, the most common is the satisfaction concept, which is often considered with regard to the kindergarten from respondents' experience. This is a subjective notion: a respondent compares the situation with personal opinion about kindergarten image on the basis of his/her own memories of preschool childhood, family traditions of attitude to children, his/her parental strategy, media background around preschool education.

Analyses of expectations and concepts about various quality aspects, such as analysis of parents' expectations about child's school readiness support and key tasks of kindergarten [4], analysis of attractiveness criteria in regard to ECEC service for parents [5], analysis of parents' opinions about their choice of kindergarten [6], consistency of concepts of parents and preschool teachers about tasks of kindergarten and school readiness provisions [7], also take place in Russian discourse. In such studies, the focus is displaced from evaluation of certain kindergarten to understanding of importance of this or that criterion by participants.

Foreign researchers also pay attention to analyses of opinions of teachers, administrators, and parents concerning quality of preschool education. That is important for agreement between researchers and practitioners in transition to new national preschool education standards, for strengthening the role of teachers concerning provision of education and upbringing of early-year-old children $[1,2,8]$.

Numerous papers contain differences in positions of parents and teachers in definition of quality aspects and their impact into child's development: parents believe that they are more responsible for development of child's self-sufficiency and social skills, and teachers consider that they are more responsible for development of academic skills, self-expression and gross-motor skills [2]. Parents firstly note professionalism of teachers regarding child's well-being; and the competences, which teachers attempt to demonstrate to parents, and the ones expected by the parents often do not coincide [9].

This doesn't contradict results of studies among separate groups of respondents. According to Maltese parents' opinion, the most important criteria are relationships established with children and families, "happiness and enthusiasm" of children at the settings. Herewith, they expect the setting's contribution to personal and social development of children, their academic achievement, preparation for school [10]. Teachers in Australia, Denmark, Estonia, Germany, Greece, and Sweden believe that preschool children learning occurs in situations promoting their social development and based on children's initiative [11]. Teachers from Sweden, Austria, and Bulgaria prioritize the attitude to kindergarten, group size, child/adult ratio, organizational climate, adult/child interaction, teachers' planning [12]. The teachers from Estonia and Turkey believe that they are responsible for children's school readiness, describe actual quality of preparation for school through development of basic reading and writing skills, social skills and knowledge, though, they are aware that children need more to be ready for school, and on this regard, they understand the lack of their professional competence [13]. At the same time, in another research among teachers of the same countries, it was stated that the links between teacher's competence and quality of preschool education could be unobvious [14].

The performed analysis demonstrates that despite differences in believes about quality in different groups of respondents, some of them are recognized as key factors for good quality. 


\section{Methods}

In order to reveal the believes of teachers and parents about good kindergarten, the anonymous survey was carried out using standard toolkit of European Quality Seal international project. The respondents' opinions were compared with the survey of 18 experts. Participation was voluntary for all respondents.

The questionnaire was based on quality criteria used in reliable tools for evaluation and development of preschool education quality: ECERS-R [15] and German Quality Catalogue [3]. The questionnaire was comprised of closed and open-ended questions. Closed questions described in details each of 52 quality criteria. Respondents answered what range of importance the characteristic seemed to be irrespective of the ECEC setting's specificity which his/her child attended or he/she worked in. The numeric scale was used for expression of respondent's opinion, where 1 was considered as not important and 7 as very important. Before the set of closed questions, the respondents represented their own key criteria, after the closed questions set, they could add supplemental criteria, which they considered as important but did not find them in the proposed list.

The participants were preschool teachers and parents of children attended the class of these teachers (one teacher and at least 8 families of children from the same class): 57 teachers and 284 parents from 26 schools with yearly childhood groups representing 8 administrative districts of Moscow, including 8 top-quality schools, 11 medium-quality schools, 5 minimum-quality schools, and 2 private ECEC settings not included in the rating.

\section{Results}

Respondents in total estimated each of the proposed criteria as high importance, most of them were estimated in excess of 5.5. The minimum mean value among parents was 4.5 , among teachers - 4.87. General priorities were teacher-child interaction (6.57 and 6.63, respectively), child well-being in the setting (6.55 and 6.63), safety (6.55 and 6.59). Among the least significant properties, there were participation of parents in development of the program (4.5 and 4.87), exemption of parents from fee (4.8 and 5.12). In addition, for teachers, transparency in results of their performance quality evaluation was the least important (5.73), for the parents - promoting non-gendered behavioural patterns (4.88).

Meanwhile, there were significant differences in evaluation of certain important aspects: for instance, "Promoting child autonomy/self-reliance" was at the 13th position for the parents and at the 22nd position for the teachers, or "Inclusion of parents" was at the 17th position for the parents and only at the 27th position for the teachers.

Experts' opinion differed from the choice of parents and teachers. The first rank was assigned to "Individualized promotion of children" (this priority did not coincide with the choice of parents and teachers in the total ranked list: for them it was the 10th and the 12th position, respectively). The second rank in experts' opinion was teacher-child interaction, which was similar to other respondents' point of view. The third position was "Times for free play", parents and teachers evaluated the rank of this criterion as 30th and 17.5th, respectively. As for the less prioritized criteria, experts' opinion coincided with other respondents' one.

Moreover, among the quality criteria of pedagogical interaction, parents mentioned health practices (6.43), and the teachers voted for cognitive development (6.54). Provisions for personal needs of teachers were one of the least significant parameters for teachers, whereas in the parents' rating, it was at a higher position.

As for family involvement, all respondents prioritized child's well-being and individualized promotion of children. The least important were exemption from fee (4.8 and 
5.12), transparency in results of teachers' performance quality evaluation (5.33 and 5.73), observation and documentation of child's development (5.5 and 5.77).

Everybody recognized participation of parents in decision making about the setting's performance as least significant (4.5 and 4.87).

Among the Pedagogical structure criteria, parents' priorities were outdoor space (6.39) and indoor space (6.27), and adult/child ratio (6.28). For teachers, the priorities were indoor space (6.6) and outdoor space (6.53), training of teachers (6.28). All respondents mentioned the "Exemption of the director from care responsibilities" criterion as the least significant parameter (5.66 and 6.02).

In open-ended questions, the most frequent words in the parents' sample were meals, group classes, pedagogical orientations, child skills and achievements, good teacher-child relationships. Teachers agreed in frequent mentioning of safety, development, environment, development of provisions, needs, comfort, respect.

\section{Discussion}

High estimations of all quality criteria evidence their acceptance by respondents. Teachers and parents often have the same opinions about these or those provisions for child's development. Neither parents nor teachers are highly interested in participation of family members in learning process, and it is not important whether a parent would pay for ECEC services. In addition, child-adult interaction, child's well-being and safety are the main priorities.

Certain data are important in the context of megalopolis: priority rank of indoor and outdoor space. This is quite expectable because of the lack of space in megalopolis, especially in old districts. General tone of teachers' answers is worth mentioning: they highlight criteria of safety, provision of needs, comfort, respect. In this case, the probable explanations are stressful nature of the profession, high level of parents' and authorities' demands, as well as organizational climate after merging of independent kindergartens into large educational complexes.

Thus, a parent, who sends the child to kindergarten, is firstly interested in quality of care, emotional comfort and safety, and not in the content of education. Underestimation of teaching aspects contradicts with the mission of the profession (to develop and to teach), decreases social status of preschool teachers in their own eyes. Teachers demonstrate higher mean values of the most of criteria, including education, in comparison with parents. Thus, it is a possible assumption that their professional growth will changing their pedagogical orientations from supervision and care to more specific educational activities.

\section{Conclusion}

Consistency between parents and teachers on key positions evidences that there are grounds for a productive dialogue about the quality of preschool education. Significant differences in some important criteria point out that Such dialogue is crucially necessary. This dialogue should be mediated by experts who can adjust public opinion towards strengthening the significance of educational function of kindergarten.

\section{References}

1. M. Karlsson Lohmander, V. Sollars, Early childhood educators' voices in shifting curricular policies and praxis, in Early Years: Making it Count. 29th EECERA Annual Conference, Aristotle University of Thessaloniki, 20-23 August 2019, Thessaloniki, 
Greece, 59 (2019)

2. M. Göl-Güven, Boğaziçi University Journal of Education, 31(1), 19-43 (2014)

3. V. Tietze, S. Fiernickel, I. Dittrich, K. Grenner, A. Hanisch, J. Marx, Evaluation and development of the quality of preschool education (Mozaika-sintez, Moscow, 2018)

4. Ye.G.Yudina, Ye.A. Krichevets, Readiness for school as seen by parents and teachers, in Trends in the development of education: who and how uses and evaluates educational standards. Materials of the XIV Annual International Scientific and Practical Conference, 16-18 February 2018, Moscow, Russia, 259-276 (2018)

5. A.K. Nysskaya, Modern preschool education. Theory and practice, 9, 24-33 (2016)

6. V.S. Sobkin, Yu.A. Khalutina, Modern preschool education. Theory and practice, 1(83), 6-18 (2018)

7. Ya.Ya. Kozmina, Modern preschool education. Theory and practice, 9, 34-41 (2016).

8. S. Philipsson, S. Garvice (Eds.), Teachers' and families' perspective in early childhood education and care. Early childhood education in the $21^{\text {st }}$ century. Vol. II (Routledge, London, 2019)

9. T. Vuorinena, A. Sandberg, S. Sheridan, P. Williams, Early Child Development and Care, 184(1), 149-159 (2014). http://dx.doi.org/10.1080/03004430.2013.773992

10. V. Sollars, Parents defining quality in early years provision, in Early Years: Making it Count. 29th EECERA Annual Conference, Aristotle University of Thessaloniki, 20-23 August 2019, Thessaloniki, Greece, 59 (2019)

11. S. Broström, A. Sandberg, I. Johansson, K. Margetts, B. Nyland, T. Frøkjær, C. Kieferle, A. Seifert, A. Roth, A. Ugaste, K. Vrinioti, Early Child Development and Care, 185(5), 824-847 (2015). http://dx.doi.org/10.1080/03004430.2014.958483

12. J. Brodin, L. Hollerer, K. Renblad, V. Stancheva-Popkostadinova, Early Child Development and Care, 185(6), 968-981 (2015). http://dx.doi.org/10.1080/03004430.2014.974035

13. K. Stein, M. Veisson, T. Õun, T. Tammemäe, Education 3-13, 47(8), 920-932 (2018). http://doi.org/10.1080/03004279.2018.1539113

14. M. Veisson, A. Kabaday, Journal of Teacher Education for Sustainability, 20(2), 5-18 (2018). https://doi.org/10.2478/jtes-2018-0011

15. T. Harms, R. Clifford, D. Cryer, Scales for a comprehensive assessment of the quality of education in a preschool education organization ECERS-R (Natsionalnoye obrazovaniye, Moscow, 2017) 